\title{
ERGONOMIA DO AMBIENTE CONSTRUÍDO: UM ESTUDO DE CASO DAS SEQUELAS DA POLIOMIELITE E AS RECOMENDAÇÕES ADAPTATIVAS DE BANHEIROS PÚBLICOS
}

\author{
VASCONCELOS, Hortência Lira (1). \\ VASCONCELOS, Angelica Lira (2). \\ (1) Universidade Federal de Pernambuco, Graduada \\ e-mail:hortencia_lira@yahoo.com.br \\ (2) Universidade Federal de Pernambuco, Graduada \\ e-mail: Ivasconcelos@gmail.com
}

\begin{abstract}
RESUMO
Em todo o mundo, milhares de pessoas convivem com as sequelas causadas pela poliomielite, comumente denominada de paralisia infantil. Doença causada pelo poliovírus. A doença foi praticamente erradicada em países com aplicação de vacina, contudo, diversos adultos convivem com sequelas irreversíveis. Dentre os ambientes comumente utilizados na vida cotidiana, o banheiro público surge como espaço necessário a todos, dentro desse contexto, este estudo objetivou a análise das sequelas deixadas pela poliomielite no organismo, com ênfase na perda de coordenação motora, e o uso do banheiro público. Para esta pesquisa foram escolhidas as cabines acessíveis dos banheiros públicos da Universidade Federal de Pernambuco - CAA, foi possível identificar diversas necessidades do usuário e propor parâmetros projetuais que proporcionem um melhor uso do ambiente.
\end{abstract}

Palavras chave: poliomielite; ergonomia; banheiro.

\begin{abstract}
Worldwide, thousands of people live with the consequences caused by poliomyelitis, commonly known as infantile paralysis. Disease caused by the poliovirus. The disease was virtually eradicated in countries with vaccine application, however, many adults live with irreversible consequences. Among the commonly used environments in everyday life, the public toilet comes as necessary space to all, in this context, this study aimed to analyze the consequences left by polio in the body, emphasizing the loss of motor coordination, and use of public toilet for this research were chosen accessible cabins of public toilets at the Federal University of Pernambuco - CAA, it was possible to identify various user needs and propose projective parameters that provide a better use of the environment.
\end{abstract}

Keywords: polio; ergonomics; WC.

\section{INTRODUÇÃO}

A Poliomielite ou paralisia infantil é uma doença infecto-contagiosa causada pelo Poliovírus. As primeiras epidemias da poliomielite ocorreram na Europa, na metade dos anos 1800, na Inglaterra, e na América do Norte na década de 1890, (FADEL et al. 1986). 


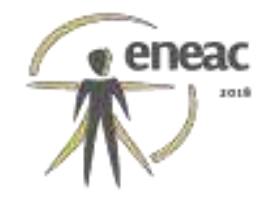

A poliomielite durante anos alarmou todo o mundo, a doença deixou um grande número de pessoas com sequelas extremas, dentre as complicações tem-se a limitação da coordenação motora, a maior parte dos afetados, necessitam do uso de cadeiras especiais para locomoção, por não possuírem total força e funcionalidade nos membros.

Nesse contexto, a Ergonomia é uma excelente ferramenta de adaptação de artefatos, às diferentes características, necessidades e limitações humanas. A ergonomia busca harmonizar a ligação humano-máquina, de modo que as tarefas, postos de trabalho, produtos, ambientes e sistemas tornem-se compatíveis com as necessidades, habilidades e limitações das pessoas. Para tanto, faz uso de dados da fisiologia, da neurofisiologia, psicofisiologia, da psicologia, da psicopatologia, da biomecânica ocupacional, bem como da anatomia e da antropometria. (SOARES e MORAES, 2010; MORAES E MONT'ALVÃO, 2010; IIDA, 2005).

Os banheiros públicos são ambientes extremamente necessários, precisam permitir o uso por parte de todos, é comum que o usuário com necessidades específicas, se depare com barreiras físicas ou não adaptações. Neste trabalho será realizado um estudo de caso, na Universidade Federal de Pernambuco, Centro Acadêmico do Agreste, com intuito de verificar a possibilidade de uso por parte de um usuário com sequelas causadas pela poliomielite.

Foi possível ao final desta pesquisa, propor parâmetros para projeto ou adaptação de banheiros públicos. No intuito de resultar em um estudo com norteamento adaptativo deste ambiente, proporcionando uma melhor qualidade no uso por parte das pessoas acometidas pela pólio, reduzindo a sensação de exclusão e evitando ocasionar acidentes.

\section{FUNDAMENTAÇÃO TEÓRICA}

O vírus da pólio se expandiu pelo mundo, acometendo uma grande quantidade de enfermos nas populações atingidas. Na Europa, a poliomielite foi reconhecida em 1800 e na América do Norte em 1890, sendo o agente infeccioso identificado em 1930.

Em 1948, conseguiu-se cultivar o Poliovírus em tecido não nervoso, depois de longos anos de pesquisa a vacina foi declarada em 12 de abril de 1955, com as campanhas de vacinação em massa a erradicação do Poliovírus foi alcançada na maior parte do globo terrestre (BARRO et al., 2004; OLIVEIRA et al., 2008).

$\mathrm{Na}$ forma paralítica da doença há inflamação e destruição da massa cinzenta do sistema nervoso central e da medula espinhal. A paralisia é classificada como espinhal, bulbar ou associada, levando à doença bulbo espinhal. A doença espinhal geralmente é assintomática com paralisia flácida.

O grau de paralisia varia de acordo com a extensão do envolvimento muscular, desde alguns grupos musculares, levando a hemiplegia ou paraplegia ou pode haver paralisia dos membros superiores e inferiores (tetraplegia).

A doença ocorre em todos os grupos etários, mas as crianças, geralmente, são mais suscetíveis que os adultos, e entre as sequelas principais, têm- se a perda de coordenação motora e enfraquecimento dos membros (Figura 01), (RECHENCHOSKI et al., 2015). 


\section{îneac}

Figura 01 - Enfraquecimento membros superiores.

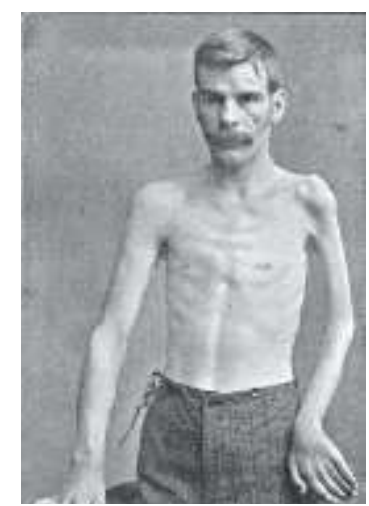

Fonte: http://neuromuscular.wustl.edu/spinal/infect.htm

Uma das principais sequelas da Poliomielite é a atrofia muscular. Segundo Oliveira (2008), a atrofia muscular residual, fraqueza e arreflexia acomete ao menos um dos membros, torna o membro fraco e sem coordenação, praticar atividades que exijam força, será de extrema dificuldade. Ainda segundo o autor, os sobreviventes da pólio que necessitam realizar atividades comuns ao dia a dia, sentem um cansaço excessivo, por possuírem grandes falhas no sistema nervoso central, atividades consideradas normais causam esgotamento.

Possuir uma necessidade física, seja ela momentânea ou definitiva, causa diversos problemas ligados ao cotidiano. A sociedade ainda não está totalmente preparada para lidar com as diversas limitações possíveis existentes, os ambientes mal projetados e as diversas barreiras físicas. Casadei (2010) enfatiza que as dificuldades encontradas nos diversos ambientes necessários à vida, tornam o cotidiano do portador de necessidade especial cada vez mais complicado, a autora ainda defende que a realização de tarefas fora do ambiente doméstico pode diminuir problemas relacionando com o isolamento social, baixa autoestima e o grande desconforto de se sentir improdutivo, recorrentes características de pessoas com necessidades.

Um grande número na sociedade de pessoas com necessidades específicas, demanda de um grande trabalho de politicas publicas voltadas a esse número de pessoas. Ampliando-se sobre este olhar, Corrêa (2014), relata que o conceito de acessibilidade está associado à filosofia do Desenho Universal constituída por enfatizar o ambiente acessível à diversidade humana, onde é necessário atender á necessidade especifica de cada pessoa e favorecer a realização das mais diversas atividades do cotidiano com maior independência, autonomia, segurança e principalmente conforto. O decreto 5.296 de dezembro de 2004 relata 0 conceito de acessibilidade no Brasil:

[...] condição para utilização, com segurança e autonomia, total ou assistida, dos espaços, mobiliários e equipamentos urbanos, das edificações, dos serviços de transporte e dos dispositivos, sistemas e meios de comunicação e informação, por pessoa portadora de deficiência ou com mobilidade reduzida. (BRASIL, 2004a, p.45-46).

Como alicerce para o norteamento desta pesquisa, guiamo-nos sob a ótica da Pesquisa Bibliográfica. Apoiados em Cervo, Bervian e da Silva (2007, p.61), nos conduzimos pelo fato da pesquisa bibliográfica se constituir na busca do domínio do estado da arte sobre determinado tema. Desta forma, nos debruçamos sobre a literatura científica com o intuito de identificar insumos teóricos que forneçam referências relacionadas às 


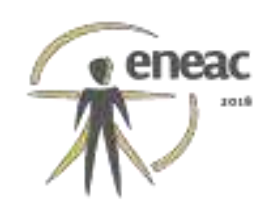

características das sequelas provenientes da Poliomielite.

Com o objetivo de evidenciar o fato de que o ambiente utilizado precisa de novos parâmetros e adaptações para que venham a ser utilizados com maior nível de conforto por pessoas com pouca capacidade motora, informações confirmadas durante a pesquisa bibliográfica, lançamos mão do Método Comparativo em concordância com Lakatos e Marconi (2011), sendo assim, o método comparativo se fez necessário para atender o objetivo de analisar a capacidade de utilização de banheiros públicos acessíveis por indivíduos que possuem ampla coordenação motora nos membros superiores, com dados da NBR 9050/2015, em contradição com as dificuldades por parte das pessoas com sequelas da pólio.

Essa pesquisa refere-se a um usuário com sequelas causadas pela poliomielite. Sequelas essas já exemplificadas durante a fundamentação deste trabalho. Fernando, o usuário escolhido para o estudo de caso, possui um grande encurtamento nos membros superiores, em conjunto com a perca de coordenação e força, causando diversas dificuldades em movimentar-se da cadeira para outro artefato, por esse motivo o estudo de caso foi realizado nos banheiros acessíveis da UFPE CAA, local onde o usuário relata possuir maiores dificuldades.

\section{2 - FUNDAMENTAÇÃO TEÓRICA}

Para a execução desta etapa foi realizada uma entrevista estruturada, em conjunto com registros fotográficos, com o intuito de verificar de forma mais específica as necessidades do usuário no ambiente do estudo de caso. Durante a etapa da entrevista, Fernando, questionado sobre as maiores dificuldades no ambiente da universidade, nos informou a falta de acessibilidade em ambientes como a fotocópia, lanchonete e área administrativa, é impossível executar tarefas normalmente, não há possibilidade de aproximação e os itens comumente estão impossibilitados de alcance.

A maior dificuldade relatada por Fernando durante o período de estadia na faculdade é o uso da cabine acessível dos banheiros, o usuário relatou a impossibilidade de autonomia, a não disposição de itens necessários o grande risco de acidentes. Com a realização dos registros fotográficos, exemplificados a seguir na etapa de análise da tarefa, foi possível realizar uma sequência demonstrando o uso, e visualizar as falhas e os requisitos necessários ao ambiente.

Figura 2 - Usuário na porta da cabine

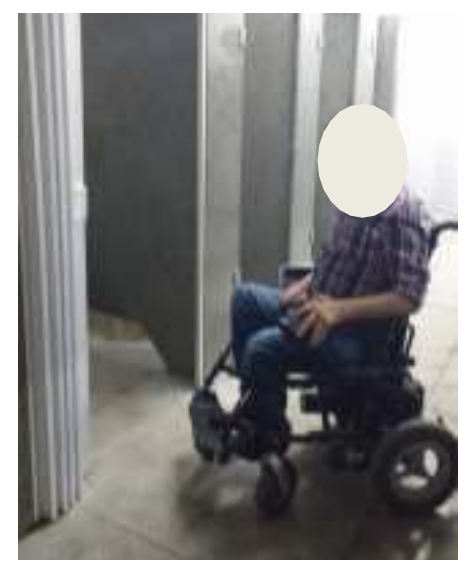

Fonte: acervo dos autores. 


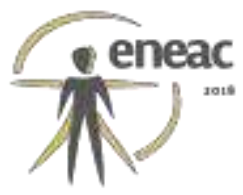

Fernando consegue adentrar na cabine (Figura 10), contudo, necessita que a porta esteja aberta, tendo que solicitar o auxilio de outras pessoas do ambiente, essa necessidade diverge da primordial função dos ambientes acessíveis, que é, possibilitar o uso com autonomia. O peso da porta e o formato do fecho impossibilitam o uso, ele não consegue fechar a porta corretamente, nesse contexto, qualquer pessoa pode adentrar no ambiente e causar um grande constrangimento.

$\mathrm{Na}$ parte interna da cabine (Figura 11), Fernando enfatiza que não consegue utilizar o banheiro acessível de todas as formas que necessita, enfatizando que apenas utiliza os banheiros da UFPE CAA, para urinar, ainda relata estar passando diversos problemas de saúde por não conseguir realizar suas necessidades fisiológicas normalmente. Ainda ressalta que, por vezes, o banheiro é encontrado muito sujo, o mesmo, não é apenas utilizado por pessoas com necessidades específicas, limitando ainda mais o acesso dele ao ambiente.

Figura 3 - Usuário dentro da cabine acessível.

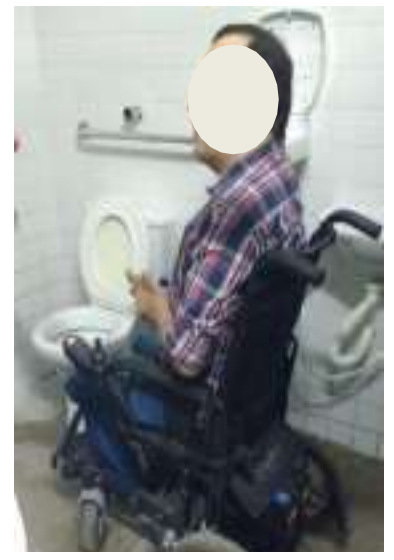

Fonte: acervo dos autores.

Em diversos momentos Fernando relata o risco de acidentes em tentar utilizar as barras de apoio, o mesmo já passou por momentos em que necessitou de auxilio de outras pessoas, e devido ao risco ele prefere não realizar suas necessidades fisiológicas durante o período que está na Universidade.

\section{3 . CONCLUSÃO}

O banheiro é um ambiente necessário à vida cotidiana, tanto privada quanto pública, o seu humano necessita realizar necessidades fisiológicas em diferentes períodos do dia. Para atender usuários que necessitam do uso da cadeira de rodas, tem-se, como já exemplificado anteriormente, a norma regulamentadora NBR 9050/2015 que define os parâmetros adaptativos exclusivos para essa parcela da sociedade.

A norma NBR 9050/2015, possui parâmetros para cadeirantes que possuam capacidade motora normal. Ao longo da pesquisa foi possível notar a impossibilidade de uso por parte do usuário em questão. Fernando não pode executar todas as suas necessidades físicas que necessita, causando grande incomodo e por vezes problemas de saúde. 


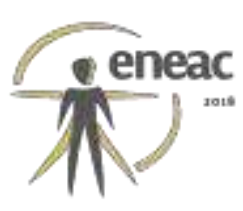

O Quadro 01 representa os itens apontados durante a pesquisa como inacessíveis e prejudiciais ao uso. Foram considerados os dados constatados durante a etapa de análise da tarefa, a entrevista foi de suma importância para os resultados dessa pesquisa. A porta do banheiro acessível, a falta de uma banqueta para transposição para o vaso sanitário, a falta de itens de higiene pós uso internos a cabine e a altura de instalação foram os itens citados e notados durante a pesquisa. Serão apresentados em detalhes no Quadro 01.

\section{Quadro 01 - Itens que prejudicam o uso}

\begin{tabular}{|c|c|}
\hline Portas das cabines & $\begin{array}{l}\text { Considerada a maior dificuldade durante por parte do usuário, pois pode } \\
\text { limitar o uso do ambiente por completo. As portas das cabines possuem um } \\
\text { peso que não possibilita que o usuário possa abrir e fechar, durante a } \\
\text { necessidade de uso Fernando precisa solicitar o auxílio de outra pessoa } \\
\text { para que a mesma abra e feche a porta. As dificuldades se estendem ao } \\
\text { fecho interno, o mesmo possuí um formato inadequado para pessoas que } \\
\text { possuem mobilidade reduzida, além de ser muito pequeno. A porta do } \\
\text { banheiro tende a permanecer aberta, apenas encostada, acarretando em } \\
\text { um receio por parte de usuário e um risco de constrangimento. }\end{array}$ \\
\hline $\begin{array}{l}\text { Altura na instalação } \\
\text { dos itens de higiene }\end{array}$ & A altura de instalação do papeleiro impossibilita o alcance do usuário. \\
\hline $\begin{array}{c}\text { Lavatório interno e } \\
\text { torneira }\end{array}$ & $\begin{array}{l}\text { A altura do lavatório interno a cabine possibilita o uso, contudo, o mesmo não } \\
\text { acontece com o formato de abertura e fechamento da torneira, o formato } \\
\text { rosca necessita de uma aplicação de forma não adequada ao usuário. Por } \\
\text { diversas vezes o banheiro é utilizado por outras pessoas que tendem a forçar } \\
\text { o fechamento da torneira tornando impossível o acionamento. Há uma falta } \\
\text { de itens para limpeza pós-uso dentro da cabine acessível, quando for } \\
\text { possível essa higiene deverá ser realizada apenas com água. }\end{array}$ \\
\hline Lavatório externo & $\begin{array}{l}\text { O lavatório externo possui uma altura não condizente com as necessidades } \\
\text { do usuário, não há possibilidade de alcance e mesmo que houvesse, as } \\
\text { torneiras possuem as mesmas características das torneiras internas a cabine } \\
\text { acessível. }\end{array}$ \\
\hline Bacia sanitária & $\begin{array}{l}\text { A falta de um apoio para realizar a transferência para o vaso sanitário limita } \\
\text { totalmente o uso, não há possibilidade de executar todas as atividades } \\
\text { necessárias, o usuário apenas consegue se posicionar na lateral do vaso e } \\
\text { não há possibilidade de passagem. Por esse motivo o usuário não consegue } \\
\text { realizar suas necessidades fisiológicas por completo durante o horário que } \\
\text { permanece na universidade. } \\
\text { Ainda sobre os itens relacionados diretamente com ao vaso sanitário tem-se } \\
\text { as barras de apoio instaladas conforme a figura } 06 \text {, as barras de nada } \\
\text { auxiliam o uso. O usuário relata que não há possibilidade de alcance e o } \\
\text { mesmo não possuir força suficiente para transporta-se de um artefato a outro. } \\
\text { Outro item ligado a bacia sanitária é a caixa de descarga que possui um } \\
\text { acionamento que não condiz com a necessidade do usuário. Mesmo que o } \\
\text { usuário consiga utilizar a bacia sanitária não conseguirá usar a descarga. }\end{array}$ \\
\hline
\end{tabular}

Fonte: elaborado pelos autores. 


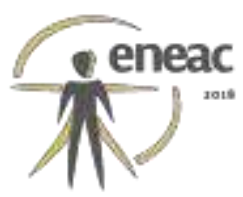

Com base nos dados colhidos durante a fundamentação, em conjunto com a análise da tarefa realizada com o usuário no ambiente escolhido para este estudo, foi possível criar prováveis alternativas para nortear uma futura adaptação, tanto para itens já instalados e insatisfatórios, como também para itens citados como faltosos, as alternativas são apresentadas no Quadro 02.

\section{Quadro 02 - Sugestões para recomendações adaptativas}

\begin{tabular}{|c|c|}
\hline Portas das cabines & $\begin{array}{l}\text { As portas deveram ser em material mais leve, que possibilite a entrada no } \\
\text { ambiente sem a necessidade de uma grande aplicação de força. O fecho da } \\
\text { porta deverá possuir um tamanho maior, e possuir um formato que se adeque } \\
\text { a pouca capacidade de pega do usuário, utilizando se possível um } \\
\text { monocomando. } \\
\text { Sendo possível o fechamento por completo da cabine, tornando o uso mais } \\
\text { seguro, individual e íntimo. Tais recomendações são necessárias devido à } \\
\text { falta de força. }\end{array}$ \\
\hline $\begin{array}{l}\text { Altura na instalação } \\
\text { dos itens de higiene }\end{array}$ & $\begin{array}{l}\text { O papeleiro deverá ser instalado mais próximo ao piso, o usuário mesmo não } \\
\text { conseguindo utilizar o vaso, pode precisar de papel higiênico. Os itens de } \\
\text { higiene pós-uso devem ser instalados mais próximos ao piso acabado, } \\
\text { possibilitando o acesso do usuário, diminuindo a necessidade de alcance. }\end{array}$ \\
\hline $\begin{array}{l}\text { Lavatório interno e } \\
\text { torneira }\end{array}$ & $\begin{array}{l}\text { O lavatório interno possui uma altura adequada, não limita o uso, contudo, o } \\
\text { formato de acionamento da torneira não possibilita que o usuário realize a } \\
\text { limpeza das mãos. A pega da torneira deverá em formato diferenciado se } \\
\text { possível em formato alavanca, possuindo a necessidade de um } \\
\text { monocomando. } \\
\text { Deve-se incluir itens de higiene dentro da cabine, para que não seja } \\
\text { necessário o uso do lavatório externo. }\end{array}$ \\
\hline Lavatório externo & $\begin{array}{l}\text { Com a adaptação do lavatório interno e a disposição de itens de higiene não } \\
\text { será necessária a adaptação do lavatório externo }\end{array}$ \\
\hline Bacia sanitária & $\begin{array}{l}\text { As recomendações para esse item são amplas, como o usuário não } \\
\text { consegue utilizar o vaso para todas as necessidades, o mesmo solicita a } \\
\text { inclusão de uma cadeira que sirva como extensão da bacia ou até mesmo o } \\
\text { uso de uma cadeira especial que possua uma abertura no assento, contudo } \\
\text { o usuário relata, que mesmo com essas adaptações, seria de extrema } \\
\text { necessidade limitar o uso do ambiente por parte de pessoas que não } \\
\text { possuam necessidades específicas. De nada adiantaria se o ambiente fosse } \\
\text { adaptado mas tivesse seus itens deteriorados ou fora de alcance. A caixa de } \\
\text { descarga acoplada deverá possuir um acionamento com alavanca e } \\
\text { monocomando possibilitando o uso. }\end{array}$ \\
\hline
\end{tabular}

Fonte: elaborado pelos autores.

É importante ressaltar que um processo adaptativo demanda de um estudo bem mais aprofundado, com parâmetros e instrumentos técnicos. Nessa pesquisa foi identificada apenas algumas das necessidades encontradas durante a pesquisa, pesquisas mais amplas 


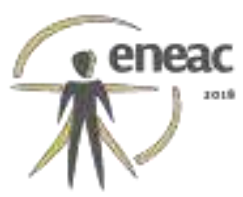

poderão trazer novos detalhes.

Essa pesquisa trouxe a visualização de que não é correto apenas adaptar um ambiente ao uso de cadeira de rodas, é necessário enfatizar as outras diversas necessidades do portador de necessidades específicas. É incompreensível que a sociedade ainda limite o acesso de pessoas com necessidades específicas a ambientes tão necessários a higiene e saúde humana, passar grande quantidade de tempo sem utilizar o banheiro, traz graves problemas ao usuário.

As barras de apoio que deveriam auxiliar na transposição do usuário de nada servem durante o uso, mesmo que elas fossem instaladas mais próximas ou possuíssem outro formato não auxiliariam, o usuário não possui força física suficiente para utiliza-las. A inclusão de uma cadeira ou base de apoio na altura da bacia sanitária seria a recomendação ideal, conforme as informações colhidas durante a entrevista e a análise da tarefa. $O$ ambiente ficará possivelmente mais acessível quando otimizada a disposição desses elementos, garantindo maior autonomia do usuário.

O referente estudo demonstrou que o acometido pela poliomielite apresenta uma série de sequelas, não só a necessidade de uso da cadeira de rodas. Deve-se ter uma visualização mais ampla das outras diversas sequelas causadas pela doença. Pode- se considerar que um grande número de pessoas com sequelas da pólio evitam conviver em ambientes sociais acessíveis, por não possuírem as mesmas capacidades de alcance e aplicação de força, de pessoas que possuem os membros superiores, considerados normais, a norma NBR 9050, deixa uma grande lacuna no atendimento a esses usuários.

Os dados gerados nessa pesquisa podem servir de norteamento para futuras adaptações. Recomenda-se uma pesquisa mais aprofundada envolvendo uma maior quantidade de usuários que possuam sequelas causadas pela pólio, o estudo deverá fazer o uso de ferramentas de medição antropométrica com intuito de validar com dados mais específicos as necessidades encontradas neste estudo de caso, podendo assim, identificar um maior número de necessidades e propor soluções mais específicas.

\section{BIBLIOGRAFIA}

ASSOCIAÇÃO BRASILEIRA DENORMAS TÉCNICAS. ABNT NBR 9050:2015 - Acessibilidade a edificações, mobiliário, espaços e equipamentos urbanos. ABNT, Rio de Janeiro. 2015.

ATTAIANESE, Erminia; DUCA, Gabriella; Human factors and ergonomic principles in building design for life and work activities: an applied methodology, Theoretical Issues in Ergonomics Science, 13:2, 187-202 - 2012.

BARABANI, Marcelo; Síndrome dificulta rotina de quem teve poliomielite - Sintomas como cansaço e dores musculares. Disponível em: http://sindromepospoliomielite.blogspot.com.br/2015/05/sindrome-dificulta-rotina-de- quem-teve.html 2003 - Acesso em 03/05/2016

BARRO; Pedro. RIBEIRO; Patricia, GASPAR; Margarida - A Poliomielite - Universidade e Evora, departamento de Biologia. 2004.

CAMPOS; Marcos Vinhal; Direitos dos Portadores de Paralisia oriunda da Poliomielite. Disponível em: http://www.revistavigor.com.br/2007/10/16/direitos-dos- portadores-de-paralisiaoriunda-da-poliomielite/.2007 - Acesso em 03/05/2016 


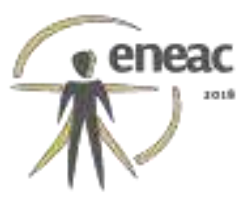

CASADEI; Juliana Rascalha . Particularidades de histórias de vida de pacientes com poliomielite e síndrome póspoliomielite. Monografia apresentada à Universidade Federal de São Paulo UNIFESP, como parte dos requisitos para obtenção do título de Especialista em Intervenções Fisioterapêuticas em Doenças Neuromusculares. 2010.

Censo 2010 - Pesquisa Nacional de Saúde - disponível em: http://censo2010.ibge.gov.br/, Acesso em: 05/05/2016.

CERVO, Amado Luiz; BERVIAN, Pedro A; SILVA, Roberto da; Metodologia Científica - 6ª Ed. 2007.

FADEL, Carlos Antonio; HARTMAN, Cristiana; MOREIRA, Célia Regina; MENDONÇA, Luciana Hoeschel; QUINTINO, Marisa; Poliomielite. Universidade Federal de Santa Caratrina - Centro de ciências da saúde - 1986.

GURGEL; Maria Aparecida. A pessoa com deficiência e sua relação com a história da humanidade. Disponível em: http://acessa-para.blogspot.com.br/2012/02/pessoa- com-deficiencia-e-suarelacao.html. Acesso em: 04/05/2016.

IIDA, Itiro. Egonomia: projeto e produção. 2ª edição. São Paulo: Edgard Blucher, 2005

LAKATOS, M.E; MARCONI, M.A; Fundamentos de metodologia cientifica, 5 ed. - São Paulo: atlas 2011.

LUZ, Maria de Lourdes; IWATA, Nara; Design Universal: vida sem barreiras. Áquila - Revista Interdisciplinar UVA • Rio de Janeiro/2013. Ano IV (n.. 9) 112-121.

MORAES, Anamaria; MONT'ALVÃO, Cláudia. Ergonomia: Conceitos e aplicações. Rio de Janeiro: $2 A B, 2010$.

OLIVEIRA; Acary Souza Bulle. QUADROS; Abrahão Augusto Juviniano - SINDROME PóSPOLIOMIELITE - Orientações para Profissionais de Saúde - Versão para Internet - São Paulo 2008.

OLIVEIRA, Bulle Souza Acary; MAYNARD, Frederick M; Sindrome Pós-Poliomielite:

Aspectos Neurológicos. Revista Neurociencias 31-34, 2002.

OLIVEIRA, Lúcia Helena, Poliomielite paralítica associada à vacina: um estudo de coorte retrospectivo de paralisias flácidas no Brasil, 1989-1995. Dissertação, ENSP/Fiocruz, 1998.

Presidência da República - Casa Civil - Subchefia para Assuntos Jurídicos - DECRETO № 5.296 DE 2 DE DEZEMBRO DE 2004. Brasília, 2 de dezembro de 2004; 1830 da Independência e 1160 da República. Disponível em: http://www.planalto.gov.br/ccivil_03/_ato20042006/2004/decreto/d5296.htm -Acesso em: 05/05/2016

RECHENCHOSKI; Daniele Zendrini; GODOI, Ananda Marques; BOTURA, Tatiana Jabor , FACCIN; Ligia Carla - Poliomielite - erradicação ou controle? Revista de Ciências Médicas e Biológicas. Salvador, v.14, n.2, p. 233-237, mai./ago.2015.

SOARES, M. M. \& MORAES, A. de. Ergonomia Princípios e Métodos. Apostila Curso de Especialização - Departamento de Design, Universidade Federal de Pernambuco, 2003.

SUS 2015 - Estratégia brasileira para contribuir com a erradicação global da poliomielite disponível em: http://portalsaude.saude.gov.br/index.php/o-

ministerio/principal/secretarias/svs/noticias-svs/22558-svs-divulga-estrategia- brasileira-paracontribuir-com-a-erradicacao-global-da-poliomielite - acesso em: 06/05/2016. 


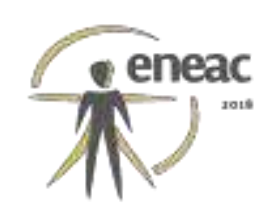

TAVARES; F.N. - O início do fim da poliomielite: 60 anos do desenvolvimento da vacina - Revista Pan-Amaz Saúde 2015; 6(1) 9-11.

VIEIRA, Vanessa; Doenças Infecciosas - Poliomielite. Disponível em:

http://patologiageraldoencasinfecciosas.blogspot.com.br/2013/07/poliomielite.html Acesso em: 04/05/2016 